\title{
BMJ Open Incidence of road traffic disabilities trending upwards in transitional China: a retrospective analysis from 1980 to 2005
}

\author{
Lan Liu, Wei Du, Lihua Pang, Gong Chen, Xiaoying Zheng
}

To cite: Liu L, Du W, Pang L, et al. Incidence of road traffic disabilities trending upwards in transitional China: a retrospective analysis from 1980 to 2005. BMJ Open 2014:4:e004297.

doi:10.1136/bmjopen-2013004297

- Prepublication history for this paper is available online. To view these files please visit the journal online (http://dx.doi.org/10.1136/ bmjopen-2013-004297)

Received 21 October 2013 Revised 8 April 2014 Accepted 22 April 2014

\section{(D) CrossMark}

Institute of Population Research, Peking University, Beijing, China

Correspondence to Professor Xiaoying Zheng; xzheng@pku.edu.cn

\section{ABSTRACT}

Objective: To evaluate the change in incidence rates of road traffic disabilities from 1980 to 2005 in China. Methods: We employed the 2006 China National Sample Survey on Disability to derive weighted number of persons with disabilities resulting from road crashes and weighted age-gender-specific population at risk by disability occurrence year. The annual incidence rate of road traffic disabilities and corresponding $95 \% \mathrm{Cl}$ were estimated. We used the World Population Prospects (WPP) and the death rate of people with disabilities (PWD) to estimate potential earlier loss of lives before 2006. Both WPP-adjusted and PWD-adjusted incidence rates of road traffic disabilities were further adjusted using the life table analysis.

Results: The WPP-adjusted incidence rate for road traffic disabilities increased over time from 1.50 (95\% Cl 1.47 to 1.52$)$ in 1980 to $11.19(95 \% \mathrm{Cl} 11.13$ to 11.25) per 100000 persons in 2005. The PWDadjusted incidence rate also increased from 1.71 (95\% $\mathrm{Cl} 1.68$ to 1.73$)$ to $11.51(95 \% \mathrm{Cl} 11.45$ to 11.57$) \mathrm{per}$ 100000 persons.

Conclusions: Road crashes disable thousands of Chinese and remain a significant population health and development problem. The increasing burden of road traffic disabilities calls for more efforts and specific strategies to improve road safety in China.

\section{INTRODUCTION}

Road crashes are a population health problem worldwide; ${ }^{2}$ however, over $90 \%$ of the global road traffic deaths occurred in low-income and middle-income countries. ${ }^{1}$ Moreover, road traffic death rates have increased rapidly in most low-income and middle-income countries experiencing socioeconomic transition, ${ }^{3}$ which were estimated to further increase by $80 \% .^{2}$

Road crashes are also a cause of non-fatal injuries, for example, for every death 50 more persons would have sustained severe road traffic injuries, ${ }^{4}$ and these casualties may survive with long-term disabilities. ${ }^{5}$

\section{Strengths and limitations of this study}

- This is the first study presenting an overview of the annual incidence rate for road traffic disabilities over two decades in China using a nationally representative survey. The unadjusted and adjusted findings consistently demonstrate that road traffic disabilities are an emerging population health problem in China.

- When applying life table analysis, we estimate annual age-gender-specific survival probability by interpolating the average difference between two adjacent values, which may be somewhat optimistic for persons with severe disability. Although we used the life table analysis to adjust for potential early-life losses among persons with road traffic disabilities, the disability incidence estimates may still be underestimated.

Consequently, heavy financial burden is imposed on healthcare systems and communities especially in developing countries, with the direct cost of approximately $1.0-1.5 \%$ of the gross national product in low-income and middle-income countries. ${ }^{2} 67$ A study conducted in the early 1990s in Mauritius indicated that an annual cost resulted from road crashes was equivalent to $£ 20$ million. ${ }^{8}$ Similarly in China, approximately 3.2 million years of lost productivity were reported from road crash mortality in $1999 .{ }^{9}$ There are few financial cost estimates for non-fatal road traffic injuries including disabilities, but increased financial burden to individual families was reported including the additional cost of prolonged care, the loss of the primary household income, higher health expenditures to achieve a standard of living equivalent to that of non-disabled people and the loss of income due to disability. ${ }^{6}$

Considering rapid motorisation is underway with an increase in the number of civilian motor vehicles by 17 -fold during 
1980-2005 from 1.8 to 31.6 million in China, ${ }^{10}$ road crashes remain an important population health problem. ${ }^{1}$ Compared with previously reported $243 \%$ increase in road traffic mortality in the late 1990s in China, ${ }^{4}$ a $27 \%$ decrease using police-collected mortality statistics during the period of 2002-2007 was revealed. ${ }^{11}$ Arguably this down turn in road traffic deaths may not comprehensively reflect road safety gain in China when comparing with a non-significant $8 \%$ increase of road traffic injuries using hospital registry statistics from 2002 to 2007. ${ }^{11}$ Nevertheless, any estimation of incidence change over time in terms of road traffic disabilities (RTDs) has not been attempted.

In this study, we aim to estimate the annual incidence rate of RTDs between 1980 and 2005, and the finding may provide additional evidence to complement previous studies on the burden of road traffic injuries in transitional China.

\section{METHODS}

\section{Data sources}

We used the China National Sample Survey on Disability which was conducted in all province-level administrative regions of mainland China by the Leading Group of China National Sample Survey on Disability and the National Bureau of Statistics in 2006. ${ }^{12}$ The survey applied multistage cluster probabilistic proportional sampling scheme to every province. ${ }^{12}$ Within each regional stratum, a four-stage sampling strategy with four natural administrative units (ie, county, town, village and community), and a sampling method of probability proportional to cluster size was applied to derive nationally representative samples. The survey comprised 734 counties (5964 communities), and a sample size of 2526145 non-institutionalised individuals. ${ }^{13}$

The survey collected demographic information such as age, gender, disabilities (absent/present) and severity of disability (mild, moderate, severe or profound) confirmed by the designated physicians using diagnostic manuals, the primary cause of a disability and the age of disability occurrence. Strict quality control measures were implemented at every step during the survey from the checking of the returned questionnaires to the checking of data entry, for example, completed surveys were reviewed and fields with missing information were clarified by site interviewers. ${ }^{13}$

As disability may generally refer to impairment in sensory or mobility functions, limitation in movements or activities or restriction in social participation, it may be defined using various diagnostic tools. ${ }^{14-17}$ In the survey, diagnostic manuals including the International Classification Functioning, Disability and Health (ICF), the 10th edition of International Statistical Classification of Diseases and Related Health Problems (ICD-10) and WHO Disability Assessment Schedule 2.0 were used to define different types of disabilities and disability severity where appropriate.
For the current study, we selected study participants as persons with physical and/or intellectual disabilities caused by road crashes. The current study dataset has no unclassifiable values for focused variables including age, gender, physician confirmed disabilities and underlying primary cause, and age of disability occurrence.

\section{Measures}

\section{Road traffic disabilities}

Disability was classified as present or absent based on a comprehensive assessment on body function impairments, activity limitations and participation restrictions. ${ }^{18}$ We consider RTD as a physical or intellectual disability resulting from road crashes such as having physical impairment (ie, loss of motor function of varying degrees or limitations in movements or activities resulting from deformed limbs or body paralysis (palsy) or from deformity caused by damage to the structure or function of those body parts involved in mobility); and/ or intellectual impairment (ie, lower than normal intellectual ability and accompanied by adaptive behaviour disorders resulted from impairment of the structure and functions of the nervous system, limiting individual activity and participation and requiring all-round, extensive, limited or intermittent support). ${ }^{13}$

\section{Annual incident rate}

Based on the age of RTD occurrence, we derived the corresponding year of disability occurrence and calculated the weighted number of persons with disabilities of different age-gender groups resulted from road crashes between 1980 and 2005. We used the World Population Prospects (WPP) defined 5-year age groups from 0 -year-olds and 1-4-year-olds to the oldest group for those who were 100 years and over. ${ }^{19}$ We employed the 2006 survey cohort to estimate the weighted age-genderspecific population. We further applied the life table methods and interpolated the average difference within a 5-year interval between two adjacent values to calculate the annual age-gender-specific population during the study period. ${ }^{20}{ }^{21}$ We calculated an annual crude incidence rate for RTDs in a given year of $t$ :

$$
\text { Incidence }^{\mathrm{t}}=\frac{\sum_{\mathrm{i}=1}^{\mathrm{k}} \mathrm{N}_{\mathrm{i}}^{\mathrm{t}}}{\sum_{\mathrm{i}=1}^{\mathrm{t}} \mathrm{N}_{\text {Total-i }}^{\mathrm{t}}} \times 100000,
$$

where i denotes the WPP defined age groups $(i=1,2,3, \ldots$, $\mathrm{k}), \mathrm{N}_{\mathrm{i}}^{\mathrm{t}}$ is the age-specific weighted number of survey participants with RTDs and $\mathrm{N}_{\text {Total-i }}^{\mathrm{t}}$ is the age-specificweighted population in China.

However, persons with RTDs may have died before the survey year of 2006, which would result in an underestimation of the incidence rate calculation. Therefore, we applied the life table methods to estimate the survival probability for persons with RTDs. ${ }^{20}{ }^{21}$ We used the WPP published life table with 5-year intervals in China from 1980 to $2005 .{ }^{19}$ As the WPP life table only provided data with 5-year intervals between 1980 and 2005, we further 
calculated the survival probability for each age group within a 5-year interval by interpolating the average difference between two adjacent values. We calculated an annual WPP-adjusted incidence rate for RTDs in the year of $t$ allowing for potential early loss of lives before the survey year:

$$
\text { Incidence }_{\text {WPP }}^{\mathrm{t}}=\frac{\sum_{\mathrm{i}=1}^{\mathrm{k}} \mathrm{N}_{\mathrm{i}}^{\mathrm{t}} / \mathrm{S}_{\mathrm{i}+(2006-\mathrm{t})}^{\mathrm{t}}}{\sum_{\mathrm{i}=1}^{\mathrm{k}} \mathrm{N}_{\text {Total-i }}^{\mathrm{t}}} \times 100000,
$$

where $S_{i+(2006-t)}^{t}$ denotes the WPP survival probability of persons with RTDs for 2006-t years; $i, \mathrm{~N}_{\mathrm{i}}^{\mathrm{t}}$ and $\mathrm{N}_{\text {Total-i }}^{\mathrm{t}}$ refer to the same denotation in formula (1).

Furthermore, we extracted the death rates of people with disabilities (PWD) in China during the period $2007-2010^{22}$ to calculate the PWD-derived survival probability based on Chiang's method ${ }^{21}$ :

$$
\mathrm{S}_{\mathrm{PWD}}=1-\left(\left(\mathrm{n} \times \mathrm{M}_{\mathrm{PWD}}\right) /\left(1+\left(1-\mathrm{a}_{\mathrm{i}}\right) \times \mathrm{n} \times \mathrm{M}_{\mathrm{PWD}}\right)\right),
$$

where $\mathrm{M}_{\mathrm{PWD}}$ is the PWD-derived average death rate, $\mathrm{n}$ refers to the age group interval, $i$ refers to the WPP-defined age groups and $\mathrm{a}_{\mathrm{i}}$ is the average number of years lived in the $i$ to $i+n$ age group interval by those dying in the interval, which is determined using Chiang's empirical estimation because it is invariant with respect to sex, race, cause of death, geographic location and other demographic variables. ${ }^{21}$ Assuming the fatal aetiological factors may have equal effects on persons with RTDs and the general population with disabilities in China, that is, persons with RTDs were assumed to die with the same death rates, we applied the PWD-derived survival probability to calculate an annual PWD-adjusted incidence rate for RTDs in the year of $t$ :

$$
\text { Incidence }_{\mathrm{PWD}}^{\mathrm{t}}=\frac{\sum_{\mathrm{i}=1}^{\mathrm{k}} \mathrm{N}_{\mathrm{i}}^{\mathrm{t}} / \mathrm{S}_{\mathrm{PWD}}}{\sum_{\mathrm{i}=1}^{\mathrm{k}} \mathrm{N}_{\text {Total-i }}^{\mathrm{t}}} \times 100000,
$$

where $S_{\text {PWD }}$ denotes the PWD survival probability of persons with RTDs; and $\mathrm{i}, \mathrm{N}_{\mathrm{i}}^{\mathrm{t}}$ and $\mathrm{N}_{\text {Total- } \mathrm{i}}^{\mathrm{t}}$ are the same denotation in formula (1).

Table 1 presents an example of calculating the WPP-adjusted incidence rate of RTDs among women between 20 and 49 years of age in 1981 (table 1). Considering the survey design, we constructed sample weights using standard weighting procedures and used SAS SURVEYFREQ procedure to estimate $95 \%$ CIs of the number of persons with RTDs. Applying the lower and upper CI limits in the formulae (1)-(3) resulted in corresponding $95 \%$ CIs for unadjusted, WPP-adjusted and PWD-adjusted incidence rate estimates.

\section{RESULTS}

Of the population with RTDs, persons with severe or profound disabilities accounted for $12.9 \%$, whereas persons with moderate disabilities or mild disabilities accounted for $23.4 \%$ and $63.7 \%$, respectively. Figure 1 shows the annual incidence rates and their corresponding 95\% CIs for RTDs per 100000 persons, Incidence, Incidence $_{\mathrm{WPP}}$ and Incidence $_{\mathrm{PWD}}$ during the period 1980-2005. The unadjusted incidence rate of RTDs, Incidence, increased from 1.21 (95\% CI 1.19 to 1.23 ) in 1980 to 10.12 (95\% CI 10.07 to 10.17 ) per 100000 persons in 2005. The Incidence ${ }_{\mathrm{WPP}}$, increased from 1.50 (95\% CI 1.47 to 1.52 ) in 1980 to 11.19 (95\% CI 11.13 to 11.25) per 100000 persons in 2005. The Incidence ${ }_{\mathrm{PWD}}$, also increased over time from 1.71 (95\% CI 1.68 to 1.73 ) in 1980 to 11.51 (95\% CI 11.45 to 11.57 ) per 100000 persons in 2005 (figure 1).

Between 1980 and 2005, the adjusted annual incidence rates per 100000 persons for RTDs of different severities all trended upwards (severe or profound disabilities from 0.06 to 2.22; moderate disabilities from 0.50 to 2.47; mild disabilities from 0.94 to 6.50 ). The annual incidence rates of RTDs for men were significantly higher than those among women in recent years. For example, the Incidence ${ }_{W P P}$ for men increased from 2.32 (95\% CI 2.28 to 2.37 ) in 1980 to 15.75 (95\% CI 15.66 to 15.85$)$ per 100000 men in 2005 , whereas the rate for women increased from 0.69 (95\% CI 0.67 to 0.71 ) in 1980 to 6.49 (95\% CI 6.43 to 6.55$)$ per 100000 women in 2005 (figure 1).

\section{DISCUSSION}

We found a significant increase in the incidence of RTDs among the Chinese population, with the number of civilian motor vehicles increasing from 1.8 million in 1980 to 31.6 million in 2005 , corresponding to a growth from 1.81 to 24.16 vehicles per 1000 population. ${ }^{10}$ Road crashes have become one of the leading causes of death and years of life lost in China recently. ${ }^{23}{ }^{24}$ Furthermore, the most recent estimates of 3.2 million years of lost productivity $^{9}$ and 14.96 million disability-adjusted life years (DALYs) ${ }^{24}$ were attributed to road crashes. Many road safety initiatives have been established in China, such as the official recognition of road safety as a national public health need ${ }^{25}$ and the introduction of compulsory seat belt use in 2004. ${ }^{26}$ Although road traffic mortalities decreased during the period 2002-2007, this may be more due to the incompleteness of the data collection rather than robust safety gain. ${ }^{11}$ As such, the current study finding of an increasing trend in RTDs reinforces that continuing efforts should be invested to improve road safety in China.

The study finding of increasing incidence rates in RTDs is consistent with the previous finding of an $8 \%$ increase of hospitalised non-fatal injuries resulting from road crashes in China. ${ }^{11}$ There are many reasons that may contribute to this increasing trend of RTDs in China, such as lack of enforcement of traffic regulations, ${ }^{27} 28$ changing sociocultural patterns including risktaking behaviours ${ }^{29} 30$ and lack of use protective gears such as helmets. ${ }^{27} 2931 \quad 32$ However, we could not examine this as information such as crash locations and 
Table 1 A hypothetical example of calculating the WPP-adjusted incidence rate of road traffic disabilities among women between 20 and 49 years of age in 1981

\begin{tabular}{|c|c|c|c|c|c|c|c|c|c|}
\hline $\begin{array}{l}\text { AGP } \\
(1) \\
\end{array}$ & $\begin{array}{l}\text { i } \\
(2)\end{array}$ & $\begin{array}{l}S_{i}^{1980} \\
(3) \\
\end{array}$ & $\begin{array}{l}S_{i}^{1985} \\
(4) \\
\end{array}$ & $\begin{array}{l}\text { AGRSP } \\
(5)\end{array}$ & $\begin{array}{l}S_{i}^{1981} \\
(6)\end{array}$ & $\begin{array}{l}N_{i}^{1981} \\
(7)\end{array}$ & $\begin{array}{l}N_{i}^{1981} / S_{i+25}^{1981} \\
(8)\end{array}$ & $\begin{array}{l}N_{\text {Total-i }}^{1981} \\
(9)\end{array}$ & $\begin{array}{l}\text { Incidence }{ }_{\mathrm{WPP}-\mathrm{i}}^{1981} \\
(10)\end{array}$ \\
\hline 20-24 & 1 & 0.90 & 0.95 & 0.01 & 0.91 & 10.00 & 29.24 & 650000 & 4.50 \\
\hline $25-29$ & 2 & 0.85 & 0.88 & 0.01 & 0.86 & 12.00 & 48.37 & 700000 & 6.91 \\
\hline $30-34$ & 3 & 0.80 & 0.85 & 0.01 & 0.81 & 15.00 & 85.24 & 750000 & 11.37 \\
\hline $35-39$ & 4 & 0.75 & 0.80 & 0.01 & 0.76 & 17.00 & 139.74 & 800000 & 17.47 \\
\hline $40-44$ & 5 & 0.70 & 0.75 & 0.01 & 0.71 & 18.00 & 220.49 & 850000 & 25.94 \\
\hline $45-49$ & 6 & 0.65 & 0.70 & 0.01 & 0.66 & 20.00 & 386.53 & 900000 & 42.95 \\
\hline Total & & & & & & & $\begin{array}{l}\sum_{\mathrm{i}=1}^{6} \mathrm{~N}_{\mathrm{i}}^{1981} / \mathrm{S}_{\mathrm{i}+25}^{1981} \\
=909.61\end{array}$ & $\begin{array}{l}\sum_{\mathrm{i}=1}^{6} \mathrm{~N}_{\text {Total-i }}^{1981} \\
=4650000\end{array}$ & $\begin{array}{l}\text { Incidence }_{\mathrm{WPP}}^{1981} \\
=19.56\end{array}$ \\
\hline
\end{tabular}

Notes: column heading specification:

(1) AGP: the WPP-defined age groups.

(2) i: the ith AGP.

(3) $S_{i}^{1980}$ : age-specific survival probability in 1980 derived from the WPP life table.

(4) $S_{i}^{1985}$ : age-specific survival probability in 1985 derived from the WPP life table.

(5) AGRSP: annual average growth rate of age-specific survival probability from 1980 to 1985 , that is, $(5)=\sqrt[5]{((4) /(3))}-1$.

(6) $\mathrm{S}_{\mathrm{i}}^{1981}$ : age-specific survival probability in 1981 , that is, $(6)=(3) \times(1+(5))$.

(7) $\mathrm{N}_{\mathrm{i}}^{1981}$ : number of survived persons in the th age group with RTDs occurred in year of 1981 and survived for 25 years.

(8) $\frac{\mathrm{N}_{\mathrm{i}}^{1981}}{\mathrm{~S}_{\mathrm{i}+25}^{1981}}$ : estimated incident number of persons in the th age group with RTDs occurred in year of 1981 after adjusted for early life loss during 1981-2006. For example, for the first age group of 20-24, we have $\frac{N_{1}^{1981}}{S_{1+25}^{1981}}=\frac{N_{1}^{1981}}{S_{1}^{1981} \times S_{2}^{1981} \times S_{3}^{1981} \times S_{4}^{1981} \times S_{5}^{1981}}$.

$\sum_{i=1}^{6} \frac{N_{i}^{1981}}{S_{i+25}^{1981}}$ : total annual number of people with RTDs.

(9) $\mathrm{N}_{\text {Total-i }}^{1981}$ : weighted population in each age group in 1981.

$\sum_{\mathrm{i}=1}^{6} \mathrm{~N}_{\text {Total-i }}^{1981}$ : weighted total number of population in 1981.

(10)Incidence $\mathrm{WPP}-\mathrm{i}_{\mathrm{i}}^{1981}$ : the estimated incidence rate of RTDs (per 100000 ) in the ith age group in 1981, that is,

$(10)=\frac{(8)}{(9)} \times 100000$.

In the last row, we calculate the estimated incidence rate of RTDs (per 100000 ) in 1981 with

Incidence $_{\mathrm{WPP}}^{1981}=\frac{\sum_{\mathrm{i}=1}^{6} \mathrm{~N}_{\mathrm{i}}^{1981} / \mathrm{S}_{\mathrm{i}+25}^{1981}}{\sum_{\mathrm{i}=1}^{6} \mathrm{~N}_{\text {Total-i }}^{1981}} \times 100000$.

RTD, road traffic disability; WPP, World Population Prospects.

use of protective gears were not included in the survey. Future studies may examine the association between disabling outcomes and various influential factors in a crash.

Without effective interventions, road crashes would become the third leading cause of DALYs worldwide in 2020, and the fifth leading cause for DALYs in the developed regions ${ }^{33}$ and the second in the developing regions. ${ }^{34}$ In China, Yang $e t a l^{24}$ reported an increase of $55.6 \%$ for DALYs caused by road crashes between 1990 and 2010. Evidence has been established to reduce injury risk among different road users by controlling the identified risk factors including speeding, drink driving and non-use of safety gears, and a risk reduction of road trauma by $40-65 \%$ by wearing seat belts. ${ }^{6}$

Among the various measures to reduce road trauma, mandatory road safety legislations accompanied by strict police enforcement and intensive mass-media programmes have been proved successful. ${ }^{35} 36$ However, only 28 countries with a population of 416 million have adequate laws that address all five key risk factors (ie, speed, drink driving, helmets, seat belts and child restraints). The majority of the world's population (approximate 93\%) is at elevated risk of road crashes due in part to lack of road safety legislations. ${ }^{1}$

In China, the compulsory road safety legislations include regulations to mandate use of seat belts, safe travel speed and zero tolerance of drunk driving. Since May 2011, drunk driving has been elevated to a criminal offence. $^{28}$ Considering that legislation enforcement could provide immediate safety benefits more quickly than any other single safety measure, ${ }^{37}$ intensive enforcement activities are expected to reduce the incidence of road trauma including deaths and disabilities to some extent. Despite these existing legislations and their enforcement in China, further efforts are warranted in terms of issuing new road safety initiatives such as compulsory child restraint use and helmet use for vulnerable road users.

A major limitation of this study was the estimation of deaths among disabled populations. Although we used the life table analysis to account for the early-life losses among persons with RTDs before 2006, the disability incidence estimates may still be underestimated as a person with RTDs may bear a higher risk of dying of diseases compared with the general population, and thus 




the unadjusted incidence rates

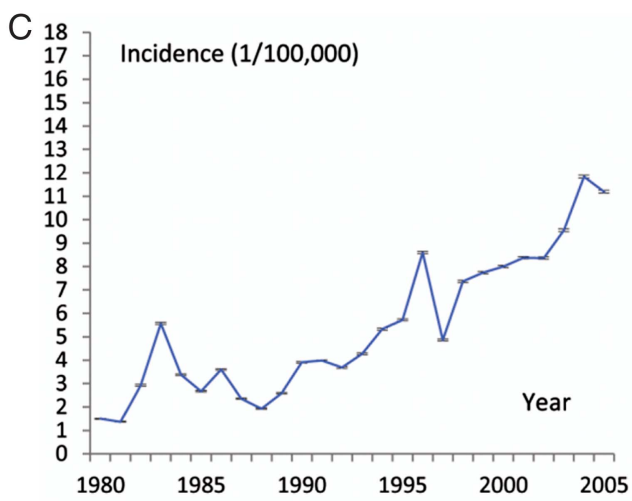

the WPP-adjusted incidence rates

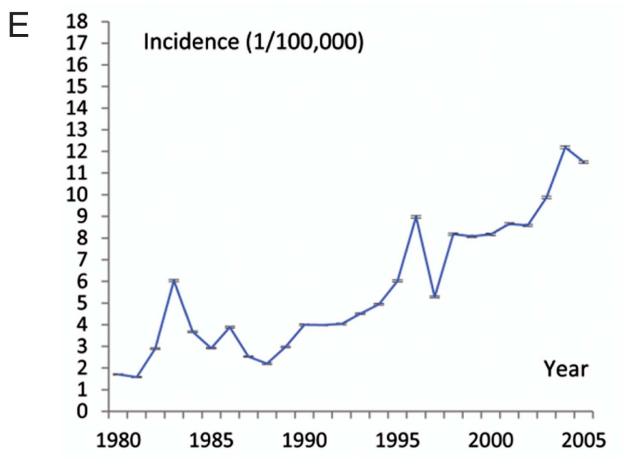

the PWD-adjusted incidence rates



the unadjusted incidence rates by gender



the WPP-adjusted incidence rates by gender



the PWD-adjusted incidence rates by gender

Note: All $95 \%$ confidence interval is indicated

Figure 1 Annual incidence rates of road traffic disabilities (per 100 000) in China 1980-2005.

was not recruited in the survey. Another limitation was the use of binary disability categorisation. Although this binary categorisation was widely applied to various study settings, ${ }^{13} 38-44$ it counted disabilities with the lowest severity the same as those with the highest such as paraplegia. Consequently, the policy implication should be interpreted with caution because crash victims with different levels of disability severity may have different levels of impaired functioning in society. Nevertheless, the study results by disability severity indicated an increase in incidence of all severity categories, and thus the current finding that the incidence of RTDs has increased over time in China was sound. Other limitations include interpolating the average difference between two adjacent values when applying life table analysis such as the calculation of annual age-genderspecific survival probability, which may be somewhat optimistic for persons with severe disability; and the use of generic diagnostic manuals to define disabilities, which may result in incomplete capture of persons with disabilities as evidenced in terms of prevalence variation between countries. Although these limitations may 
further underestimate the incidence rates we calculated, the adjusted results indicated a similar finding of an upward trend for RTDs in China. Therefore, the study findings are reliable but somewhat conservative.

\section{CONCLUSION}

RTDs have become a significant population health problem in China. Further efforts to reduce RTDs are warranted. Future road safety initiatives may focus on translating established effective injury countermeasures into local settings to save lives, prevent disabilities and other injurious outcomes resulting from road crashes in China.

Acknowledgements The authors thank the provincial and municipal federations of disabled people for their support in data collection and management.

Contributors XZ conceived the original idea for the study; all authors contributed to the conceptual development, literature review, data analysis, critical revision of the first manuscript and contributed to subsequent drafts.

Funding National Key Project (973: No. 2007CB5119001), State Key Funds of Social Science (Project Research on Disability Prevention Measurement in China: No. 09\&ZD072), National Yang Zi Scholar Program, 211 and 985 projects of Peking University (№. 20020903).

Competing interests None.

Ethics approval The survey was approved by the State Council.

Provenance and peer review Not commissioned; externally peer reviewed.

Data sharing statement No additional data are available.

Open Access This is an Open Access article distributed in accordance with the Creative Commons Attribution Non Commercial (CC BY-NC 3.0) license, which permits others to distribute, remix, adapt, build upon this work noncommercially, and license their derivative works on different terms, provided the original work is properly cited and the use is non-commercial. See: http:// creativecommons.org/licenses/by-nc/3.0/

\section{REFERENCES}

1. WHO. Global status report on road safety: time for action. Geneva, Switzerland: World Health Organization, 2009.

2. World Bank. Confronting 'Death on Wheels': making roads safe in Europe and Central Asia (Report No. 51667-ECA). Washington: The World Bank, 2009.

3. Lozano R, Naghavi M, Foreman K, et al. Global and regional mortality from 235 causes of death for 20 age groups in 1990 and 2010: a systematic analysis for the Global Burden of Disease Study 2010. Lancet 2012;380:2095-128.

4. Mock C, Kobusingye O, Anh LV, et al. Human resources for the control of road traffic injury. Bull World Health Organ 2005;83:294-300.

5. Ghaffar A, Hyder AA, Masud TI. The burden of road traffic injuries in developing countries: the 1st national injury survey of Pakistan. Public Health 2004;3:211-17.

6. Peden M, Scurfield $\mathrm{R}$, Sleet $\mathrm{D}$, et al. eds. World report on road traffic injury prevention. Geneva, Switzerland: World Health Organization, 2004.

7. Jacobs G, Aeron-Thomas A, Astrop A. Estimating global road fatalities (TRLReport No. 445). Crowthorne: Transport Research Laboratory, 2000.

8. Department for International Development. Guidelines for estimating the cost of road crashes in developing countries (Project R7780). Crowthorne, Berkshire: Department for International Development, 2003.

9. Zhou Y, Baker TD, Rao K, et al. Productivity losses from injury in China. Inj Prev 2003;9:124-7.

10. National Bureau of Statistics of China. China statistical yearbook Beijing: China Statistics Press, 1981-2006.
11. Hu GP, Baker T, Baker SP. Comparing road traffic mortality rates from police-reported data and death registration data in China. Bull World Health Organ 2011;89:41-5.

12. Communiqué on major statistics of the second China national sample survey on disability. (In English) Beijing: Leading Group of the Second China National Sample Survey on Disability \& Nationa Bureau of Statistics of the People's Republic of China, 2006. http:// www.cdpf.org.cn/english/contactus/content/2008-04/14/content_ 84989.htm (accessed 17 Dec 2013).

13. Zheng $X Y$, Chen $G$, Song XM, et al. Twenty-year trends in the prevalence of disability in China. Bull World Health Organ 2011;11:788-97.

14. Leonardi M, Bickenbach J, Ustun TB, et al. The definition of disability: what is in a name? Lancet 2006;368:1219-21.

15. WHO. World report on disability. Geneva, Switzerland: World Health Organization, 2011.

16. Freedman VA, Martin LG, Schoeni RF. Recent trends in disability and functioning among older adults in the United States: a systematic review. JAMA 2002;288:3137-46.

17. Sagardui-Villamor J, Guallar-Castillón P, García-Ferruelo M, et al Trends in disability and disability-free life expectancy among elderly people in Spain: 1986-1999. J Gerontol A Biol Sci Med Sci 2005:60:1028-34.

18. WHO. International classification of functioning, disability and health Geneva, Switzerland: World Health Organization, 2001.

19. United Nations, Department of Economic and Social Affairs, Population Division. World population prospects: the 2010 revision New York, USA: United Nations, 2011. http://esa.un.org/unpd/wpp/ Documentation/publications.htm (accessed 23 May 2013).

20. Siegel JS, Swanson DA. The methods and materials of demography. 2nd edn. San Diego, California: Elsevier Academic Press, 2004

21. Namboodiri K, Suchindran CM. Life table techniques and their applications. Orlando, Florida: Academic Press, 1987.

22. Chen SJ. Death level of persons with disabilities in China. (In Chinese) [dissertation] Beijing: Peking University, 2011.

23. Wang SY, Li YH, Chi GB, et al. Injury-related fatalities in China: an under-recognized public-health problem. Lancet 2008;372 1765-73.

24. Yang GH, Wang $Y$, Zeng $Y X$, et al. Rapid health transition in China, 1990-2010: findings from the Global Burden of Disease Study 2010. Lancet 2012;381:1987-2015.

25. Development and Research Center of State Council. Research on road traffic safety in China. (In Chinese) Beijing: Industrial Economic Research Department, Development and Research Center of State Council, 2007.

26. WHO. Road safety in the western pacific region. Geneva Switzerland: World Health Organization, 2009.

27. Ameratunga S, Hijar M, Norton R. Road-traffic injuries: confronting disparities to address a global-health problem. Lancet 2006;367:1533-40

28. Alcorn T. Uncertainty clouds China's road-traffic fatality data. Lancet 2011;378:305-6.

29. Sharma BR. Road traffic injuries: a major global public health crisis. Public Health 2008;12:1399-406.

30. Hyder AA, Ghaffar A, Sugerman DE, et al. Health and road transport in Pakistan. Public Health 2006;120:132-41.

31. Dong XM, Peng L, Wang SY. The research progress of the intervention of road traffic injury. (In Chinese) Chin J Public Health 2012:5:569-71.

32. Schopper D, Lormand JD, Waxweiler R, eds. Developing policies to prevent injuries and violence: guidelines for policy-makers and planners. Geneva, Switzerland: World Health Organization, 2006.

33. Murray CJ, Lopez AD. Global mortality, disability, and the contribution of risk factors: global burden of disease study. Lancet 1997;349:1436-42.

34. Murray CJ, Lopez AD. Alternative projections of mortality and disability by cause 1990-2020: global burden of disease study. Lancet 1997;349:1498-504.

35. ETSC (European Transport Safety Council). Seat belts and child restraints: increasing use and optimizing performance. Brussels: ETSC, 1996.

36. Ashton SJ, Mackay GM, Camm S. Seat belt use in Britain under voluntary and mandatory conditions. Proc Am Assoc Automot Med Annu Conf 1983;27:65-75.

37. OECD and ITF (International Transport Forum). Towards zero: ambitious road safety targets and safe system approach. Paris: OECD, 2008.

38. Manton KG, Corder L, Stallard E. Chronic disability trends in elderly United States populations: 1982-1994. Proc Natl Acad Sci USA 1997;94:2593-8. 
39. Manton KG, Gu XL. Changes in the prevalence of chronic disability in the United States black and nonblack population above age 65 from 1982 to 1999. Proc Natl Acad Sci USA 2001;98:6354-9.

40. Mollica RF, Sarajlić N, Chernoff M, et al. Longitudinal study of psychiatric symptoms, disability, mortality, and emigration among Bosnian refugees. JAMA 2001;286:546-54.

41. Cardozo BL, Bilukha OO, Crawford CAG, et al. Mental health, social functioning, and disability in postwar Afghanistan. JAMA 2004;292:575-84.
42. Hardy SE, Gill TM. Recovery from disability among community-dwelling older persons. JAMA 2004;291: 1596-602.

43. Gill TM, Allore HG, Holford TR. Hospitalization, restricted activity, and the development of disability among older persons. JAMA 2004;292:2115-24.

44. Von Bonsdorff MB, Leinonen R, Kujala UM, et al. Effect of physical activity counseling on disability in older people: a 2-year randomized controlled trial. J Am Geriatr Soc 2008;56:2188-94. 